\title{
Phenotypic variation of floral organs in Malus using frequency distribution functions
}

Ting Zhou ${ }^{1,2}$, Junjun Fan ${ }^{1,2,3}$, Mingming Zhao ${ }^{1,2,4}$, Donglin Zhang ${ }^{3}$, Qianhui Li $i^{1,2}$, Guibin Wang ${ }^{1,2}$, Wangxiang Zhang ${ }^{1,2,4^{*}}$ and Fuliang $\mathrm{CaO}^{1,2^{*}}$

\begin{abstract}
Background: Phenotypic diversity of floral organs plays an important role in plant systematic taxonomy and genetic variation studies. Previous research have focused on the direction of variation but disregarded its degree. Phenotypic variation (including directions and degrees) of 17 floral traits from wild to cultivated crabapples were explored by comparing their distributions and deviations in three different dimensions: floral organ number, size, and the shape.

Results: Except for petal number, petal length / petal width, and sepal length / sepal width, the analyzed floral traits of cultivated crabapples all showed downward distributed box bodies in box plot analysis and left deviations of fitted curves in frequency distribution function analysis when compared to the wild, which revealed consistent variation directions of petaloid conversion (pistils or stamens $\rightarrow$ petals), size miniaturization (large $\rightarrow$ small), and shape narrowness (petal shape: circular $\rightarrow$ elliptic; sepal shape: triangular $\rightarrow$ lanceolate). However, only seven floral traits exhibited significant differences in box plot analysis, while all of the traits in frequency distribution function analysis were obviously offset. The variation degrees were quantitatively characterized by sizing traits $>$ shaping traits > numbering traits and by horizontal dimensions > radial dimensions.

Conclusions: Frequency distribution function analysis was more sensitive than the box plot analysis, which constructed a theoretical basis for Malus flower type breeding and would provide a new quantitative method for future evaluation of floral variation among different groups of angiosperms at large.
\end{abstract}

Keywords: Malus spp., Floral variation, Direction, Degree, Frequency distribution

\section{Background}

Crabapples (Malus spp.) are small trees and shrubs in the rose family, valued for their charming flowers, colorful small fruits $(\leq 5 \mathrm{~cm})$, and diverse growth habits. They also have an added advantage of wide environmental adaptability, facilitating their world-wide prominence as landscape and gardens focal points [1-3]. After a long period of natural selection and crossbreeding, Malus germplasm present a high level of diversity, with a steadily increasing number of varieties and cultivars in relation to their wild ancestors [4-7]. While nearly 1200 Malus taxa are recorded in Fiala's "Flowering Crabapple" book, less than 5\%

\footnotetext{
* Correspondence: malus2011@163.com; cfl1957@qq.com

${ }^{1}$ College of Forestry, Nanjing Forestry University, Nanjing 210037, China

Full list of author information is available at the end of the article
}

are semi-double or double flowered. Additionally, germplasm with larger flowers are also rare, resulting in a scarcity of double-flowered and novel-typed cultivars available in today's market [8].

Flowers are one of the most ornamental features of garden plants [9-11]. They display extremely high variation in size, color, structure, and function, which are the products of continuous remodeling to adapt to different environmental conditions and pollinators and the important foundations for germplasm innovations [12-19]. Currently, most floral variation studies have been restricted to the anatomical examinations and genetic interpretations for their development on the basis of phylogenetics and molecular genetics, combining with the $\mathrm{ABC}(\mathrm{DE})$ and the quartet models

(C) The Author(s). 2019 Open Access This article is distributed under the terms of the Creative Commons Attribution 4.0 International License (http://creativecommons.org/licenses/by/4.0/), which permits unrestricted use, distribution, and 
[20-28]. Moreover, variation analyses mainly occurred above the species level (at the macro level, mainly determined by paleontology and comparative morphology methods) [29-31]. Based on phenotypes and statistical principles, few studies were carried out with more intuitive estimations of floral variation below the species level (at the micro level, mostly determined by genetics, ecology, and low-level systematics methods) [30, 31]. Chu et al. (2009) summarized the main phenotypic variation of Malus floral organs based on intuitive experience and comparative morphology, which had been widely accepted by researchers [32-34]. These results, however, were relatively imprecise because of the subjectivity of the methods. Furthermore, these studies did focused on the direction of variation and disregarded its degree.

Using box plot and frequency distribution function analyses, phenotypic variation of floral organs from wild to cultivated crabapples were explored to: (1) determine the variation rules (including directions and degrees) governing floral changes between the two groups in three different dimensions: floral organ number, size, and the shape; (2) compare the effect of different analytical methods on generating the variation rules; and (3) provide a theoretical basis for the inheritance and improvement of Malus germplasm.

\section{Results}

Box plot analysis of phenotypic variation of floral organs between wild and cultivated crabapples

Figure 1 shows box plots for 17 phenotypic traits reflecting Malus floral organ number, size, and shape. Comparative analyses of distributions and differences between the two groups were carried out, one including 25 wild crabapples and the other including 108 cultivated ones. Except for petal number, petal length / petal width, and sepal length / sepal width, all cultivated crabapples' box bodies of the other floral traits showed downward distributions relative to the wild. Specific distributions of all the phenotypic traits were as follows:

In terms of floral organ number (Fig. 1-I), petal number, pistil number, and petal, pistil and stamen number of cultivated crabapples were distributed across a larger range that completely encompassed the distributions of wild crabapples (the proportions of transgressive individuals were 4.6, 23.1 and $6.5 \%$, respectively). However, with regards to the stamen number and the pistil and stamen number, smaller distribution ranges were shown in the cultivated relative to the wild, although certain transgressive individuals (smaller individuals) still existed (the proportions of transgressive individuals were 2.8 and $4.6 \%$, respectively). No significant differences were determined among these numbering traits between the two groups $(P$ values were $0.2896,0.1021,0.4922$, 0.1959 , and 0.1394 , respectively).

In terms of floral organ size (Fig. 1-II), larger distribution ranges were shown in flower diameter, petal length, sepal length, sepal width, and pedicel length of cultivated crabapples. Among them, distribution ranges of flower diameter and petal length of cultivated crabapples completely encompassed the ranges of wild ones (the proportions of transgressive individuals were both $5.6 \%$ ). Downward distribution trends were presented in sepal length and sepal width, with smaller values in cultivated crabapples than the wild; whereas for the pedicel length, the upward distribution trend was presented together with higher values (the proportions of transgressive individuals were 9.3, 15.7 , and $5.6 \%$, respectively). On the contrary, sizing traits of petal width, claw length, pistil length, stamen length and pedicel thickness of cultivated crabapples were distributed across a smaller range. Distribution ranges of claw length and pistil length of cultivated crabapples were completely encompassed by those of the wild. And downward distribution trends were presented in petal width and pedicel thickness, with smaller values in cultivated crabapples than the wild; whereas the upward distribution trend was presented in stamen length together with higher values (the proportions of transgressive individuals were 5.6, 5.6, and $0.9 \%$, respectively). Except for pedicel length $(P=$ $0.9660)$, pistil length $(P=0.0567)$, petal length $(P=$ $0.0783)$, and claw length $(P=0.4040)$, the other six sizing traits of flower diameter, petal width, sepal length, sepal width, stamen length, and pedicel thickness, all showed significant differences between the two groups $(P$ values were $0.0244,0.0005,0.0001$, $0.0001,0.0237$, and 0.0001, respectively).

In terms of floral organ shape (Fig. 1-III), petal length / petal width and sepal length / sepal width of cultivated crabapples were both distributed across a larger range that completely encompassed the distribution ranges of those in wild crabapples (the proportions of transgressive individuals were 8.3 and 7.4\%, respectively). Significant variation was presented in petal length / petal width between wild and cultivated groups $(P=0.0030)$; however, differences in sepal length / sepal width did not reach the significant level $(P=0.5298)$.

\section{Frequency distribution function analysis of phenotypic variation of floral organs between wild and cultivated crabapples}

For a clearer analysis of floral variation from wild to cultivated crabapples, frequency distribution functions of all the 17 above-mentioned phenotypic traits were fitted (Fig. 2). Except for petal number, which followed a 


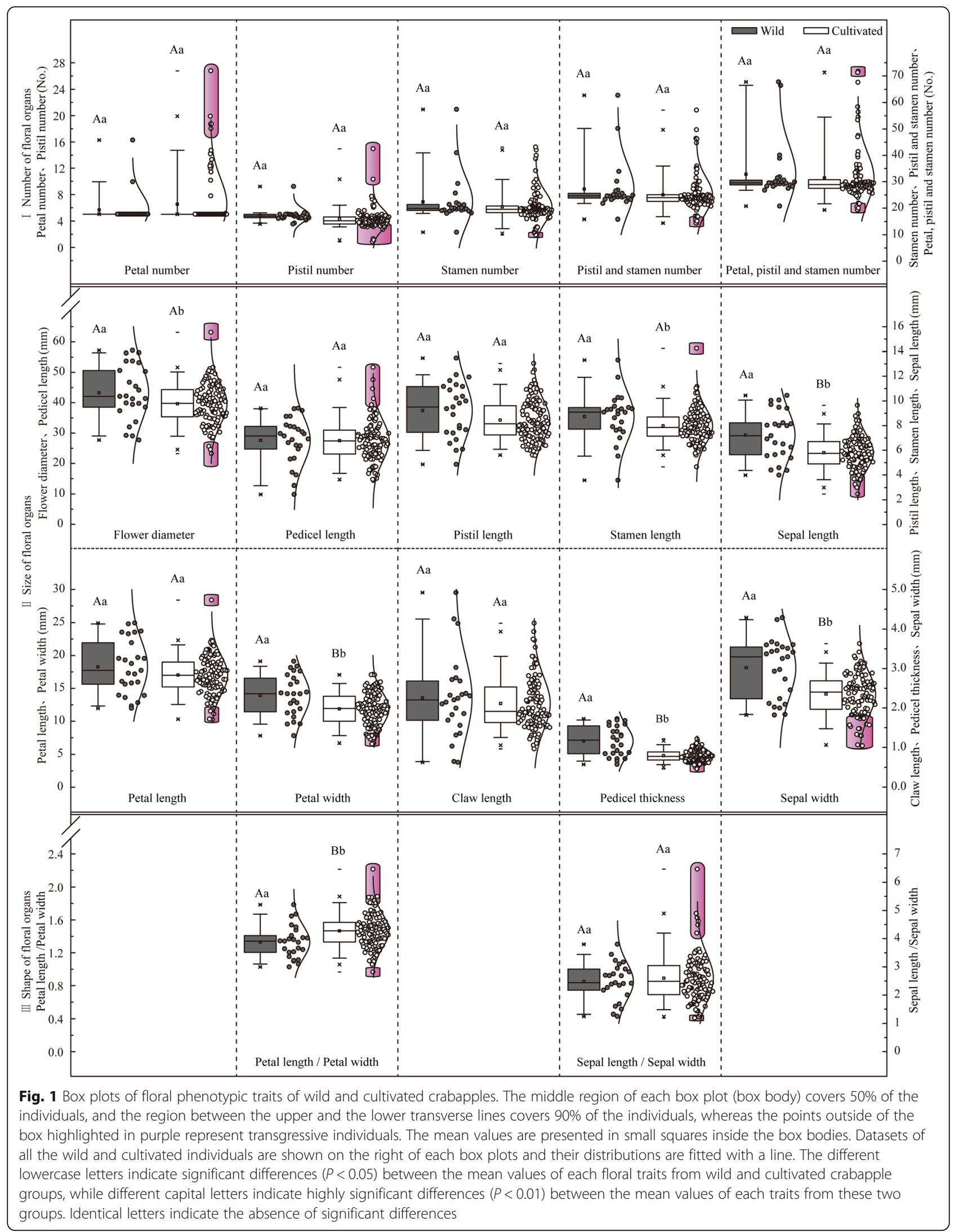




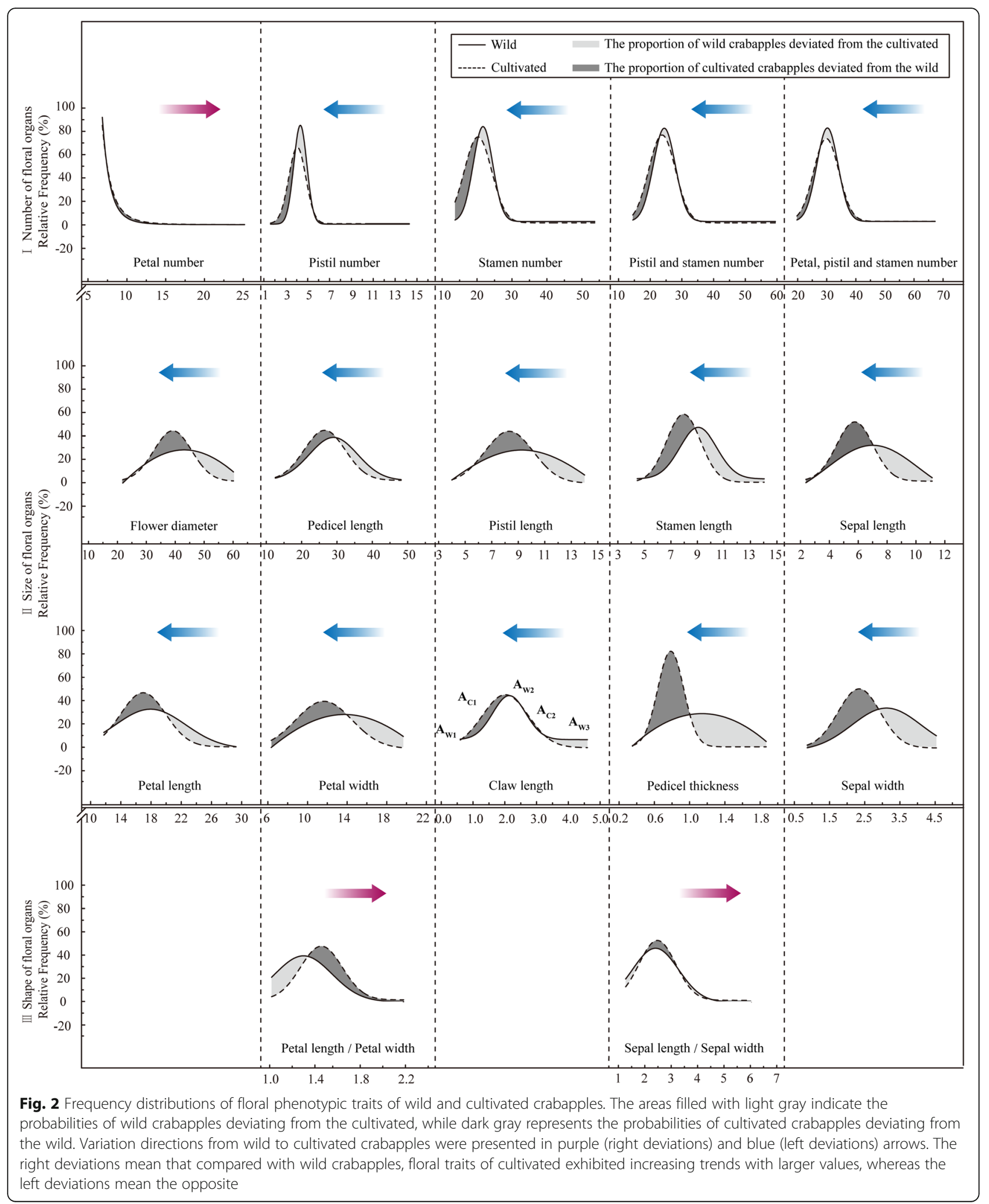

power function distribution $\left(R^{2}=0.9931-0.9972\right)$, all the other floral traits followed the normal distribution $\left(R^{2}=\right.$ 0.8625-0.9991) (Table 1).
From wild crabapples to the cultivated, the power distribution function of petal number showed a right deviation (increasing trend), while normal distribution 


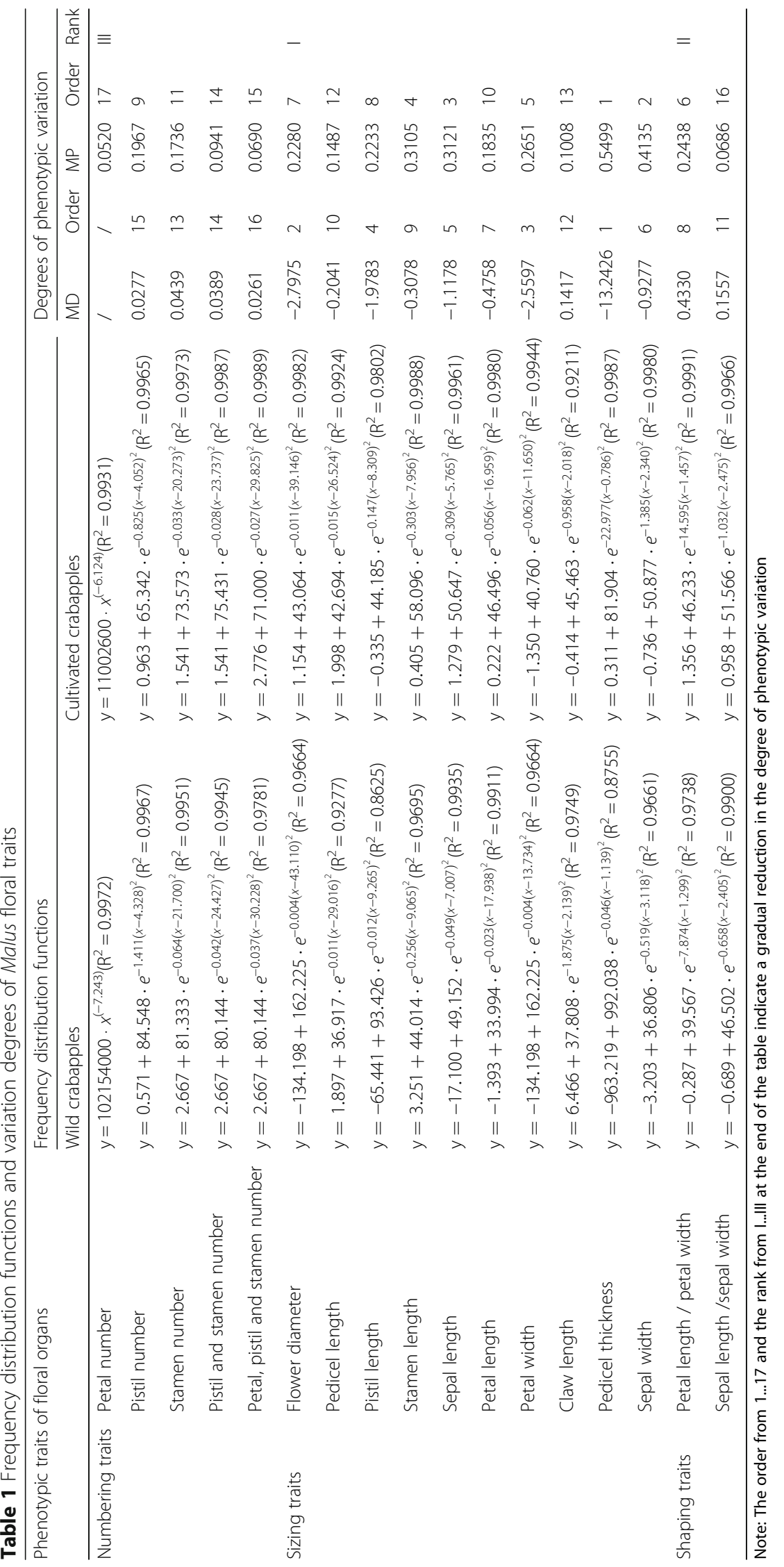


functions of the other numbering traits (pistil number, stamen number, pistil and stamen number, and petal, pistil and stamen number) showed the opposite, which indicated that additional petals in cultivated crabapples might arise from petaloid conversions of pistils or stamens during the doubling processes (Fig. 2-I). Consistent trends of left deviations (decreasing trends) were shown in all the sizing traits (Fig. 2-II), while normal distribution functions of the shaping traits both showed the contrary (Fig. 2-III).

To quantitatively express the degree of phenotypic variation of floral organs between wild and cultivated crabapples, two characteristic parameters; namely, misregistration distance (MD) and misregistration probability (MP), were calculated (Table 1). Significant positive correlation was shown between MD and MP $(r=0.7880, P=0.0000)$, confirming the validity of these two parameters. Overall, the sizing traits of floral organs showed the highest degree of variation, followed by the shaping and numbering traits. Phenotypic variation occurred higher in the horizontal dimension (pedicel thickness, petal width, and sepal width) than that in the radial dimension (pedicel length, petal length, and sepal length).

\section{Discussion}

Additional petals in cultivated crabapples arose from petaloid conversions of pistils or stamens during the long period of natural selection and crossbreeding

"Double" refers to flowers with more than one petal whorl or additional petals [35]. This phenomenon can be produced by either neoheterotopy or homoheterotopy. Neoheterotopy refers to an increase in the number of petal whorls in sympetalous flowers [36, 37], whereas homoheterotopy refers to the petaloid conversion of pistils and stamens [38-44] or bracts and sepals to construct additional petals [45-48]. Chu (2009) proposed that additional petals in cultivated crabapples were petaloid stamens [32], which had been acknowledged by many researchers. In this study, however, results were different. With an increasing trend of petal number, pistil number and stamen number of cultivated crabapples both decreased in a relatively equivalent degree $(\mathrm{MP}$ pistil number $=0.1967, \mathrm{MP}$ stamen number $=0.1736$; $\mathrm{MD}$ pistil number $=0.0277, \mathrm{MD}$ stamen number $=0.0439$ ), suggesting that multiple petals might be derived from pistils or stamens. The incomplete agreement between these two viewpoints described above could be mainly due to the differences in materials and methods used. Chu's study was mainly based on scattered discoveries, while a total of 133 Malus taxa were investigated in the present study, including 25 wild crabapples (accounting for $71.4 \%$ of total wild species recorded in the flora of China) and 108 cultivated ones (accounting for more than $50.0 \%$ of total cultivars that could be found in nurseries). Among the cultivated crabapples were 18 semi-double or double types, accounting for approximately $69.2 \%$ of the documented double types in Fiala's (1994) "Flowering Crabapple" book [8]. The representativeness of these research materials, to a certain extent, determined the reliability of this study results. Regarding the research methods, a comparative morphological method with a certain subjectivity was applied in Chu's study, which resulted in less precise conclusions. Instead, quantitative assessment based on statistical principles was adopted in the present study, which revealed the origin of the doubling phenomenon in cultivated crabapples more clearly and provided a more precise theoretical basis for Malus double-typed cultivars breeding.

\section{Non-additive effects contributed to the inhomogeneous miniaturization of floral size in cultivated crabapples}

Compared to the wild crabapples, 10 sizing traits of the cultivated exhibited a consistent trend of miniaturization with inhomogeneous variation degrees. Decrease in petal length resulted in smaller flower diameter $\left(P_{\text {petal length }}<\right.$ $P$ claw length), while larger degree of variation in the horizontal rather than in the radial dimension led to smaller and narrower floral shapes (MP petal length $=0.1835$, MP petal width $=0.2651, \mathrm{MP}$ sepal length $=0.3121$, and MP sepal width $=0.4135$ ). To account for this miniaturization, nonadditive effects (including dominant and epistasis effects) were proposed [49, 50]. Although Malus taxa originate from wild species, their genotypes are highly heterozygous after long-term natural selection and crossbreeding. According to the dominance hypothesis, dominant alleles are favored over recessive alleles for the growth and development of individuals [51]. Self-crossing or inbreeding of these heterozygous individuals will therefore increase the production of homozygotes in hybrids and expose the harmful traits represented by recessive genes, which will lead to the hybrid depression and significantly reduce the probability of heterosis [52-56]. Additionally, Li (2007) proposed that in $F_{1}$ hybrid of Gerbera jamesonii, the average values of flower diameter, pedicel length and ray floret were significantly smaller than those of their parents, which may be due to the one-way selection in the process of breeding and the large amount of non-additive effects reserved by asexual reproduction on the preservation of selected cultivars. Once sexual reproduction occurs, the possibility of heterosis may be reduced, resulting in a decrease in average values of hybrid group's traits [57]. Do this one-way selection, as well as the different fixation and heredity of non-additive effects produced by asexual and sexual reproduction, also exist in the previous breeding process of Malus taxa, which can lead to the depression of all sizing traits in the progeny? These questions deserve further exploration. Nevertheless, transgressive individuals with 
higher values still existed in sizing traits of flower diameter, petal length, stamen length, and pedicel length (the proportions of transgressive individuals were 5.6, 5.6, 0.9, and $5.6 \%$, respectively), which would provide a possibility for further innovations of Malus germplasm, such as large-flowered cultivars.

\section{Frequency distribution function analysis was more sensitive than box plot analysis, revealing clearer phenotypic variation of Malus flowers}

Plants can evolve on both the macro and micro levels. Evolution at the level of genera and higher taxonomic levels (interfamily, etc.) can be regarded as macroevolution, reflecting the origins and phylogenetic processes of large-scale alterations in plant taxa during long geological ages. In contrast, evolution within genera (inter-species and inter-cultivar) can be regarded as microevolution, reflecting the evolutionary processes of smallscale alterations in plant taxa during shorter time periods [30]. The significant differences at the level of observation between macro- and micro-evolution determine the differences in their respective research methods. The former is mainly using methods of paleontology and comparative morphology, while the latter is mainly using methods of genetics, ecology and low-level systematics [31]. In this study, phenotypic variation of floral organs between wild and cultivated crabapples represents the micro level. However, previous researchers mainly depended on intuitive experience and adopted the comparative morphological method for analysis [32-34]. This method can only roughly reveal the variation directions because of its highly subjective, leading to less reliable and imprecise results. To reveal the variation rules more objectively, accurately and thoroughly, two methods of box plot analysis (method I) and frequency distribution function analysis (method II), were applied in the present study. The variation directions revealed by both methods were consistent. However, only seven phenotypic traits; namely, flower diameter, stamen length, sepal length, petal width, pedicel thickness, sepal width, and petal length / petal width, exhibited significant differences in method I, whereas in method II, frequency distribution functions of all floral traits were obviously offset. Thus, method II was more sensitive than method I. Method I reflected the relationship between the (arithmetic) mean values that indicated the differences of two groups. These mean values, however, concealed the overall alterations. Method II reflected not only the differences in the distribution centers of two groups (mathematical expectation, $\Delta \mu$ ) but also the misregistration of the probability distribution $(\Delta \sigma)$. Both the misregistration distance (MD) and misregistration probability (MP), which are quantitative indices for exploring phenotypic variation (including directions and degrees) between different groups, could therefore be calculated.

\section{Conclusions}

Phenotypic variation of floral organs between wild and cultivated crabapples were mainly characterized as petaloid conversion, size miniaturization, and shape narrowness. Traits reflecting floral organ size reflected the highest degree of variation, followed by shaping and numbering traits. Higher degree of phenotypic variation occurred in the horizontal dimension, rather than in the radial dimension. Frequency distribution function analysis revealed clearer variation rules of floral organs in Malus than box plot analysis, which constructed a theoretical basis for Malus flower type breeding and would provide a new quantitative method for future evaluation of phenotypic variation among different groups in angiosperms at large.

\section{Methods \\ Experimental site overview}

The experimental site is situated at $32^{\circ} 42^{\prime} \mathrm{N}$ latitude and $119^{\circ} 55^{\prime} \mathrm{E}$ longitude. It has a northern subtropical monsoon climate with four distinctive seasons, $16.5^{\circ} \mathrm{C}$ annual average temperature, $800-1000 \mathrm{~mm}$ annual precipitation and a $251 \mathrm{~d}$ frost-free period. The soil type is sandy loam with $\mathrm{pH} 7.2$ and fertile soil layers. The terrain is flat with a $1.5 \mathrm{~m}$ groundwater level and good irrigation and drainage conditions.

\section{Plant materials}

A total of 133 Malus taxa (including 25 wild and 108 cultivated crabapples) were collected from the national repository of Malus spp. germplasm (Yangzhou City, Jiangsu Province, China) (Table 2). All Malus trees were between seven and ten years old, which enabled them to enter the full bloom phase. Thirty individuals of each cultivar were planted in a row at $2 \mathrm{~m}$ apart with $3 \mathrm{~m}$ between rows.

\section{Test methods}

The experiment was carried out in Spring 2017 (MarchApril). Ten plants of each cultivar were randomly selected. Three typical, standard and consistent full-bloom flowers of each plant were collected from the middle of the tree and the branch toward the sunny side, yielding 30 flowers in total. Then, all flowers were immediately loaded into a cooler and taken to the laboratory for further use.

Seventeen phenotypic traits of Malus floral organs were evaluated, including five numbering, ten sizing, and two shaping traits (Table 3), with samples straightened and pressed flat (Fig. 3). Thirty replicates were measured for each trait. 
Table 2 The list of Malus taxa collected from the national repository of Malus spp. germplasm (Yangzhou City, Jiangsu Province,

\begin{tabular}{|c|c|c|c|c|}
\hline \multirow{2}{*}{$\frac{\text { No. Wild crabapples }}{1 \text { Malus angustifolia }}$} & \multicolumn{4}{|l|}{ No. Cultivated crabapples } \\
\hline & 26 M. 'Abundance' & 53 M. 'Golden Raindrop' & 80 M. 'May's Delight' & 107 M. 'Royal Gem' \\
\hline 2 M. baccata & 27 M. 'Adams' & 54 M. 'Gorgeous' & 81 M. 'Molten Lava' & 108 M. 'Royal Raindrop' \\
\hline 3 M. domestica var.binzi & 28 M. 'Adirondack' & 55 M. 'Guard' & 82 M. 'Neville Copeman' & 109 M. 'Royalty' \\
\hline 4M. floribunda & 29 M. 'Almey' & 56 M. halliana 'Pink Double' & 83 M. 'Perfect Purple' & 110 M. 'Selkirk' \\
\hline $5 \mathrm{M}$. fusca & 30 M. 'Ballet' & 57 M. halliana 'Pink Double NFU' & 84 M. 'Pink Princess' & 111 M. 'Sentinel' \\
\hline 6 M. halliana & 31 M. 'Black Jade' & 58 M. halliana 'Pink Pillar' & 85 M. 'Pink Spires' & 112 M. 'Shelley' \\
\hline $7 \mathrm{M}$. hupehensis & 32 M. 'Brandywine' & 59 M. halliana 'Waxy' & 86 M. 'Praire Rose' & 113 M. 'Show Time' \\
\hline $8 \mathrm{M}$. ioensis & 33 M. 'Bride' & 60 M. 'Harvest Gold' & 87 M. 'Prairifire' & 114 M. 'Sieboldii NFU' \\
\hline 9 M. kirghisorum & 34 M. 'Butterball' & 61 M. 'Hillier' & 88 M. 'Professor Sprenger' & 115 M. 'Snow Winter' \\
\hline 10 M. mandshurica & 35 M. 'Candymint' & 62 M. 'Hopa' & 89 M. 'Profusion' & 116 M. 'Snowdrift' \\
\hline 11 M. micromalus & 36 M. 'Cardinal' & 63 M. 'Hydrangea' & 90 M. 'Purple Gem' & 117 M. 'Spring Glory' \\
\hline $12 \mathrm{M}$. orientalis & 37 M. 'Centurion' & 64 M. 'Indian Magic' & 91 M. 'Purple Pendula' & 118 M. 'Spring Sensation' \\
\hline 13 M. platycarpa & $38 \mathrm{M}$. 'Cinderella' & 65 M. 'Indian Summer' & 92 M. 'Purple Prince' & 119 M. 'Spring Snow' \\
\hline 14 M. prunifolia & 39 M. 'Coccinella' & 66 M. 'Irene' & 93 M. 'Purple Spring' & 120 M. 'Strawberry Jelly' \\
\hline 15 M. rockii & 40 M. 'Coralburst' & 67 M. 'John Downie' & 94 M. 'Radiant' & 121 M. 'Sugar Tyme' \\
\hline 16 M. sargentii & 41 M. 'Darwin' & 68 M. 'Kelsey' & 95 M. 'Rainbow' & 122 M. 'Superstar' \\
\hline $17 \mathrm{M}$. sieversii & 42 M. 'David' & 69 M. 'King Arthur' & 96 M. 'Red Baron' & 123 M. 'Sweet Sugartyme' \\
\hline $18 \mathrm{M}$. sieversii subsp. xinjinensis & 43 M. 'Diamond' & 70 M. 'Klehm's Improved Bechtel' & 97 M. 'Red Great' & 124 M. 'Thunderchild' \\
\hline 19 M. sikkimensis & 44 M. 'Dolgo' & 71 M. 'Lancelot' & 98 M. 'Red Jade' & 125 M. 'Tina' \\
\hline 20 M. spectabilis & 45 M. 'Donald Wyman' & 72 M. 'Lemoinei' & 99 M. 'Red Jewel' & 126 M. 'Van Eseltine' \\
\hline 21 M. sylvestris & 46 M. 'Eleyi' & 73 M. 'Lisa' & 100 M. 'Red Nessy' & 127 M. 'Velvet Pillar' \\
\hline 22 M. toringoides & 47 M. 'Everest' & 74 M. 'Liset' & 101 M. 'Red Sentinel' & 128 M. 'Weeping Madonna' \\
\hline 23 M. tschonoskii & 48 M. 'Fairytail Gold' & 75 M. 'Lollipop' & 102 M. 'Red Splendor' & 129 M. 'White Cascade' \\
\hline $24 \mathrm{M}$. turkmenorum & 49 M. 'Firebird' & 76 M. 'Louisa' & 103 M. 'Regal' & 130 M. 'Winter Gold' \\
\hline \multirow[t]{3}{*}{25 M. xiaojinensis } & 50 M. 'Flame' & 77 M. 'Louisa Contort' & 104 M. 'Robinson' & 131 M. 'Winter Red' \\
\hline & 51 M. 'Furong' & 78 M. 'Makamik' & 105 M. 'Roger's Selection' & 132 M. 'Yellow Jade' \\
\hline & 52 M. 'Golden Hornet' & 79 M. 'Mary Potter' & 106 M. 'Rudolph' & 133 M. × zumi 'Calocarpa' \\
\hline
\end{tabular}

\section{Data analysis}

\section{Box plot analysis and one-way ANOVA}

Origin 9.0, DPS 7.0, and Adobe Illustrator CS5 software were used. The box plots were drawn such that the middle section (box body) covered $50 \%$ of the observation area, the section between the upper and the lower transverse lines covered $90 \%$ of the observation area, and values outside of the box were outliers. The box bodies, mean values, and outlier values were the focus of this study. Box bodies were used to explore the variation directions of each floral traits from wild to cultivated crabapples by comparing their relative positions (downward distribution with smaller values or upward distribution with higher values), whereas mean values were served to determine the significance of differences between the two groups using Duncan multiple-comparison test $(P$ values of $<0.05$ and $<$ 0.01 were considered significant and highly significant, respectively), and the outliers were applied to reflect transgressive information, which would be of importance for Malus germplasm innovations.

\section{Frequency distribution function analysis}

Origin 9.0, Mathematica 9.0.1, and Adobe Illustrator CS5 software were used. Frequency distribution functions of 17 phenotypic traits of floral organs were fitted based on 6-10 frequency bins and variation rules (including directions and degrees) were explored. Except for petal number, which followed a power function distribution $\left(\mathrm{y}=a x^{b}\right)$, all the other floral traits followed the normal function distribution $\left(y=A+B \cdot e^{\frac{C(x-\mu)^{2}}{\sigma^{2}}}\right)$. Parameters of misregistration distance (MD) and misregistration probability (MP) were constructed, aiming at quantitatively expressing the degrees of phenotypic 
Table 3 Phenotypic traits of floral organs used in this study

\begin{tabular}{|c|c|c|c|}
\hline Type of the traits & No. & Trait descriptor & Remarks \\
\hline \multirow[t]{5}{*}{ Numbering traits } & 1 & Petal number & Counted \\
\hline & 2 & Pistil number & Counted \\
\hline & 3 & Stamen number & Counted \\
\hline & 4 & Pistil and stamen number & Calculated \\
\hline & 5 & Petal, pistil and stamen number & Calculated \\
\hline \multirow[t]{10}{*}{ Sizing traits } & 6 & Flower diameter & Measured in $\mathrm{mm}$ \\
\hline & 7 & Petal length & Measured in $\mathrm{mm}$ \\
\hline & 8 & Petal width & Measured in $\mathrm{mm}$ \\
\hline & 9 & Claw length & Measured in $\mathrm{mm}$ \\
\hline & 10 & Pistil length & Measured in $\mathrm{mm}$ \\
\hline & 11 & Stamen length & Measured in $\mathrm{mm}$ \\
\hline & 12 & Sepal length & Measured in $\mathrm{mm}$ \\
\hline & 13 & Sepal width & Measured in $\mathrm{mm}$ \\
\hline & 14 & Pedicel length & Measured in $\mathrm{mm}$ \\
\hline & 15 & Pedicel thickness & Measured in $\mathrm{mm}$ \\
\hline \multirow[t]{2}{*}{ Shaping traits } & 16 & Petal length / Petal width & Calculated \\
\hline & 17 & Sepal length / Sepal width & Calculated \\
\hline
\end{tabular}

variation of floral organs between wild and cultivated crabapples:

a. The misregistration distance (MD) between two groups was calculated according to the characteristic parameters of the normal distribution function as follows:

$$
M D=\frac{\Delta \mu \pm \Delta \sigma}{R_{90}}=\frac{\left(\mu_{C}-\mu_{W}\right) \pm\left(\sigma_{C}-\sigma_{W}\right)}{R_{90}}
$$

Where $\mu_{C}$ and $\mu_{W}$ are mathematical expectations of the random variables of cultivated and wild crabapples, respectively, that follow a normal distribution, and $\sigma_{C}$ and $\sigma_{W}$ are standard deviations of the random variables of the two groups, respectively, that follow a normal distribution. $R_{90}$ is the range representing $90 \%$ of the observation area of cultivated crabapple's box plot, which reduces the interference of the $10 \%$ of individuals belonging to the outliers. $R_{90}$ can be used as a dividend to standardize the data. In the formula, the sign ' \pm ' depends on the product of $\Delta \mu$ and $\Delta \sigma$. It is '-' when the product is positive and ' + ' when the product is negative.

b. The misregistration probability (MP) was calculated according to the misregistration area of the probability distribution function curve as follows:

$$
M P(\%)=\frac{A_{W 1}+A_{W 2}+A_{W 3}}{2}+\frac{A_{C 1}+A_{C 2}}{2}
$$

where $A_{W 1}, A_{W 2}$ and $A_{W 3}$ are the probabilities of the area

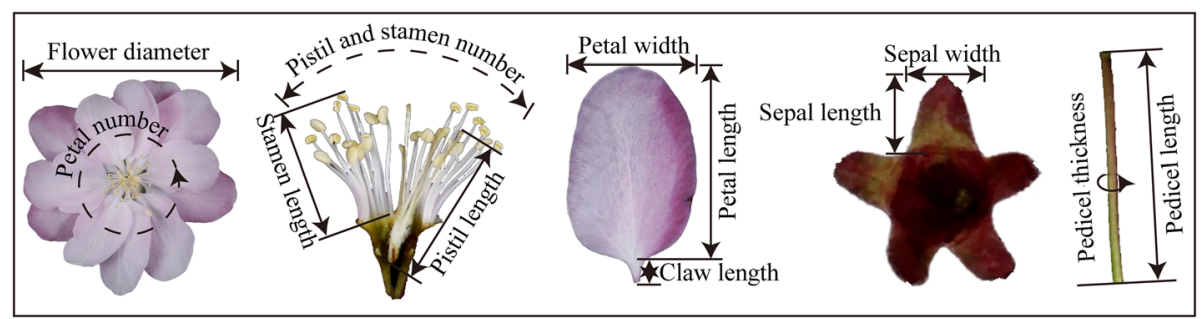

Fig. 3 Schematic diagram of the tests on phenotypic traits of floral organs. The three numbering traits of petal number, pistil number, and stamen number in Malus spp. were counted for the average of 30 representative flowers. And the ten sizing traits were measured with samples straightened and pressed flat. Phenotypic traits of the others (pistil and stamen number, petal, pistil and stamen number, petal length to width, and sepal length to width) were calculated 
that were formed by the misregistration between wild and cultivated crabapples relative to the total area formed by the $\mathrm{X}$-axis and the curve of the probability distribution function of the wild crabapples; and $A_{C 1}$ and $A_{C 2}$ are the probabilities of the area that were formed by the misregistration between cultivated and wild crabapples relative to the total area formed by the $\mathrm{X}$-axis and the curve of the probability distribution function of the cultivated crabapples.

\section{Abbreviations \\ MD: Misregistration distance; MP: Misregistration probability}

\section{Acknowledgements}

We thank Yousry A. El-Kassaby and other anonymous reviewers for their critical and helpful comments and suggestions.

\section{Authors' contributions}

TZ and WZ conceived and designed the experiment. TZ, JF, MZ, and QL collected samples and measured all the phenotypic traits. TZ, JF, MZ, QL and $W Z$ analyzed the phenotypic variation (including directions and degrees) from wild to cultivated crabapples. TZ and WZ wrote the manuscript. TZ, WZ, $D Z, G W$, and FC revised the manuscript. All authors read and approved the final manuscript.

\section{Funding}

The study was funded by the Key Research and Development Program of Modern Agriculture in Jiangsu Province (BE2019389), Priority Academic Program Development of Jiangsu Higher Education Institution (PAPD) (164010018), the Science and Technology Support Program of Jiangsu Province (BE2017375-2), and the fund for Independent Innovation of Agricultural Sciences in Jiangsu Province [CX (16) 1005-4-1]. The funding bodies were involved in the cultivation of Malus germplasm, collection of data, and writing of the manuscript.

\section{Availability of data and materials}

A total of 133 Malus taxa (including 25 wild and 108 cultivated crabapples) were collected from the national repository of Malus spp. germplasm (Yangzhou City, Jiangsu Province, China). The datasets used and analyzed during the current study could be available from the corresponding author on request.

\section{Ethics approval and consent to participate}

Not applicable.

\section{Consent for publication}

Not applicable.

\section{Competing interests}

The authors declare that they have no competing interests.

\section{Author details}

${ }^{1}$ College of Forestry, Nanjing Forestry University, Nanjing 210037, China. ${ }^{2}$ Co-Innovation Center for Sustainable Forestry in Southern China, Nanjing Forestry University, Nanjing 210037, China. ${ }^{3}$ Department of Horticulture, University of Georgia, Athens, GA 30602, USA. ${ }^{4}$ Yangzhou Crabapple Horticulture Company Limited, Yangzhou 225200, China.

\section{Received: 6 November 2018 Accepted: 21 November 2019}

\section{1.}

\section{References}

1. Wyman D. Trees for American gardens. New York: Macmillan; 1955.

2. Höfer M, Mams EA, Sellmann J, Peil A. Phenotypic evaluation and characterization of a collection of Malus species. Genet Resour Crop Evol. 2014:61:943-64

3. Lisandru TT, Füstös A, Dumitraş A, Mitre V. Flower development of ornamental crabapple according to BBCH scale. Bulletin UASVM Hortic. 2017:74:147-8.
4. Muzher BM, Younis RAA, El-Halabi O, Ismail OM. Genetic identification of some Syrian local apple(Malus sp.) cultivars using molecular markers. Res Agric Biol Sci. 2007;3:704-13.

5. Ulukan $\mathrm{H}$. The evolution of cultivated plant species: classical plant breeding versus genetic engineering. Plant Syst Evol. 2009;280:133-42.

6. Brown SK. Apple (Malus $\times$ domestica). New York: Springer; 2012

7. Mratinić E, Akšić MF. Phenotypic Diversity of apple (Malus sp.) germplasm in south serbia. Braz Arch Biol Technol. 2012;55:349-58.

8. Fiala JL. Flowering crabapples: the genus Malus. Portland: Timber Press; 1994.

9. Endress PK. The flowers in extant basal angiosperms and inferences on ancestral flowers. Int J Plant Sci. 2001;162:1111-40.

10. Maere S, De BS, Raes J, Casneuf T, Van Montagu M, Kuiper M, et al. Modeling gene and genome duplications in eukaryotes. Proc Natl Acad Sci U S A. 2005:102:5454-9.

11. Becker A, Alix K, Damerval C. The evolution of flower development: current understanding and future challenges. Ann Bot. 2011;107:1427-31.

12. Armbruster WS. Evolution of floral form: electrostatic forces, pollination, and adaptive compromise. New Phytol. 2001;152:181-3.

13. Benlloch R, Berbel A, Serranomislata A, Madueño F. Floral initiation and inflorescence architecture: a comparative view. Ann Bot. 2007:100:659-76.

14. Sargent RD, Goodwillie C, Kalisz S, Ree RH. Phylogenetic evidence for a flower size and number trade-off. Am J Bot. 2007:94:2059-62.

15. Goodwillie C, Sargent RD, Eckert CG, Elle E, Geber MA, Johnston MO, et al. Correlated evolution of mating system and floral display traits in flowering plants and its implications for the distribution of mating system variation. New Phytol. 2010;185:311-21.

16. Mojica JP, Kelly JK. Viability selection prior to trait expression is an essential component of natural selection. Proc Biol Sci. 2010;277:2945-50.

17. Dudash MR, Hassler C, Stevens PM, Fenster CB. Experimental floral and inflorescence trait manipulations affect pollinator preference and function in a hummingbird-pollinated plant. Am J Bot. 2011:98:275-82.

18. Endress PK. Evolutionary diversification of the flowers in angiosperms. Am J Bot. 2011:98:370-96.

19. Johnson K, Lenhard M. Genetic control of plant organ growth. New Phytol. 2011:191:319-33.

20. Coen ES, Meyerowitz EM. The war of the whorls: genetic interactions controlling flower development. Nature. 1991:53:31-7.

21. Theissen G. Development of floral organ identity: stories from the MADS house. Curr Opin Plant Biol. 2001:4:75-85.

22. Theissen G, Saedler H. Floral quartets. Nature. 2001;409:469-71.

23. Li Y, Li Y. Morphological studies on floral organ development of the flowers with single- and Triple-whorled petals in Lisianthus (Eustoma grandiflorum). Acta Hortic Sin. 2005;32:458-62.

24. Baum DA, Hileman LC. A developmental genetic model for the origin of the flower. In: Ainsworth C, editor. flowering and its manipulation (Annual Plant Reviews, vol. 20). Oxford: Blackwell Publishing Ltd; 2006. p. 1-27.

25. Hernández-Hernández T, Martínez-Castilla LP, Alvarez-Buylla ER. Functional diversification of B MADS-box homeotic regulators of flower development: Adaptive evolution in protein-protein interaction domains after major gene duplication events. Mol Biol Evol. 2007:24:465-81.

26. Kramer EM. Understanding the genetic basis of floral diversity. Bioscience. 2007;57:479-87.

27. Mondragón-Palomino M. Perspectives on MADS-box expression during orchid flower evolution and development. Front Plant Sci. 2013:4:377-85.

28. Li L, Yu XX, Guo CC, Duan XS, Shan HY, Zhang R, et al. Interactions among proteins of floral MADS-box genes in Nuphar pumila (Nymphaeaceae) and the most recent common ancestor of extant angiosperms help understand the underlying mechanisms of the origin of the flower. J Syst Evol. 2015;53:285-96.

29. Bemer M, Angenent GC. Floral organ initiation and development. J R Asiat Soc. 2009;100:29-36

30. Reznick DN, Ricklefs RE. Darwin's bridge between microevolution and macroevolution. Nature. 2009;457:837-42.

31. Xu B. An overview of macroevolution on the viewpoint of microevolution Acta Botanica Yunnanica. 1991;13:101-12.

32. Chu AX. Research on the cultivar classification of ornamental crabapples in Henan. Nanjing: Nanjing Forestry University; 2009.

33. Liu ZQ, Tang GG. A study on cultivar classification system of Malus halliana Koehne. J Nanjing Forestry Univ. 2004;28:101-6.

34. Qian GZ. The taxonomic study of the genus Malus Mill. Nanjing: Nanjing Forestry University; 2005 
35. RHJ S. double flower. In: Basra AS, editor. Encyclopedic Dictionary of Plant Breeding and Related Subjects. New York: Food Products Press; 2003. p. 139

36. Nitasaka E. Insertion of an En/Spm-related transposable element into a floral homeotic gene DUPLICATED causes a double flower phenotype in the Japanese morning glory. Plant J. 2003;36:522-31.

37. Li ZR, Peng Q, Ji ZC, Gao KY, Yi LX, Liao HM, et al. Floral vascular bundle systemanatomical observation of double flower Jasminum mesnyi Hance. Hunan Agric Sci. 2016;5:5-7.

38. Akita Y, Horikawa Y, Kanno A. Comparative analysis of floral MADS-box genes between wild-type and a putative homeotic mutant in lily. J Hortic Sci. 2008:83:453-61.

39. Akita Y, Nakada M, Kanno A. Effect of the expression level of an AGAMOUSlike gene on the petaloidy of stamens in the double-flowered lily, 'Elodie'. Sci Hortic. 2011;128:48-53.

40. Ao Y, Wang Y, Chen L, Wang T, Yu HY, Zhang ZX. Identification and comparative profiling of microRNAs in wild-type Xanthoceras sorbifolia, and its double flower mutant. Genes Genomics. 2012;34:561-8.

41. Heijmans K, Morel P, Vandenbussche M. MADS-box genes and floral development: the dark side. J Exp Bot. 2012;63:5397-404.

42. Liu Z, Zhang D, Liu D, Li F, Lu H. Exon skipping of AGAMOUS homolog PrseAG in developing double flowers of Prunus lannesiana (Rosaceae). Plant Cell Rep. 2013;32:227-37.

43. Noor SH, Ushijima K, Murata A, Yoshida K, Tanabe M, Tanigawa T, et al. Double flower formation induced by silencing of C-class MADS-box genes and its variation among petunia Cultivars. Sci Hortic. 2014;178:1-7.

44. Sharifi A, Oizumi K, Kubota S, Bagheri A, Shafaroudi SM, Nakano M, et al. Double flower formation in Tricyrtis macranthopsis, is related to low expression of AGAMOUS, ortholog gene. Sci Hortic. 2015;193:337-45.

45. Zhang H, Ren S. Flora reipublic popularis sinicae. Beijing: Science Press; 1998.

46. Cheng J. The genetics and breeding of garden plants. Beijing: China Forestry Press; 2001.

47. Zhu G. The potential role of B-function gene involved in floral development for double flowers formation in Camellia changii Ye. Afr J Biotechnol. 2011; 10:541-8.

48. Galimba KD, Tolkin TR, Sullivan AM, Melzer R, Theißen G, Di Stilio VS. Loss of deeply conserved C-class floral homeotic gene function and C- and E-class protein interaction in a double-flowered ranunculid mutant. Proc Natl Acad Sci U S A. 2012:109:2267-75.

49. Bouvet JM, Makouanzi G, Cros D, Vigneron PH. Modeling additive and nonadditive effects in a hybrid population using genome-wide genotyping: prediction accuracy implications. Heredity. 2016;116:146-57.

50. Bolormaa S, Pryce JE, Zhang Y, Reverter A, Barendse W, Hayes BJ, et al. Nonadditive genetic variation in growth, carcass and fertility traits of beef cattle. Genet Sel. Evol. 2015;47:26.

51. Fu D, Xiao M, Hayward A, Jiang GJ, Zhu LR, Zhou QH, et al. What is crop heterosis: new insights into an old topic. J Appl Genet. 2015;56:1-13.

52. Hufford KM, Mazer SJ. Plant ecotypes: genetic differentiation in the age of ecological restoration. Trends Ecol Evol. 2003;18:147-55.

53. Cheng J, Liu Q. Garden plant genetics and breeding. Beijing: China Forestry Press; 2010.

54. Gul R, Khalil IH, Shah SMA, Ghafoor A. Heterosis for flower and fruit traits in tomato (Lycopersicon esculentum Mill.). Afr J Biotechnol. 2010;9:4144-51.

55. Nnungu SI, Uguru MI. Expression of heterosis in floral traits and fruit size in tomato (Solanum lycopersicum) hybrids. J Trop Agric, Food, Environ Ext. 2014;13:24-9.

56. Ryder P, Mckeown PC, Fort A, Spillane C. Epigenetics and heterosis in crop plants. In: Alvarez-Venegas R, Peña CDL, Casas-Mollano JA, editors. Epigenetics in plants of agronomic importance: fundamentals and applications. Switzerland: Springer International Publishing; 2014. p. 13-31.

57. Li SC, Li SB, Jiang YL, Yang CM, Wu LF. Genetic performance of primary ornamental traits in $F_{1}$ hybrids of Gerbera jamesonii bolus intervarietal hybridization varietal hybridization. J Yunnan Agric Univ. 2007;22:197-201.

\section{Publisher's Note}

Springer Nature remains neutral with regard to jurisdictional claims in published maps and institutional affiliations. 